\title{
Internal On-line Partial Discharge Analysis of 68.75 MVA Generator Stator Winding Insulation
}

\author{
Waluyo $^{1}$, Siti Saodah ${ }^{2}$, Eltha Hidayatullah ${ }^{3}$ \\ ${ }^{1,3}$ Department of Electrical Engineering, National Institute of Technology (Itenas), Bandung, Indonesia \\ ${ }^{2}$ Department of Energy Conversion, Bandung State Polytechnic (Polban), Bandung, Indonesia
}

\section{Article Info \\ Article history: \\ Received Feb 4, 2016 \\ Revised May 26, 2016 \\ Accepted Jun 15, 2016}

\section{Keyword:}

Generator

On-line

Partial discharge

Stator

Winding insulation

\begin{abstract}
Partial discharge is a phenomenon of electron ionization occurs due to concentrated electric field in a different edge plane. This phenomenon will be investigated by an electric field measurement in a measuring point. The internal partial discharge will give the insulation damage effect on a generator stator winding due to void existence. This manuscript presents the measurement results of the on-line internal partial discharge on the stator winding insulation of 68.75 MVA generator. It used the resistant temperature detector method and $\mathrm{CM} 2000^{\mathrm{TM}}$. The results were classified into three conditions based on the voids in the generator stator insulation, the internal delamination and the surface discharge.
\end{abstract}

Copyright (c) 2016 Institute of Advanced Engineering and Science. All rights reserved.

\section{Corresponding Author:}

Waluyo,

Department of Electrical Engineering,

National Institute of Technology (ITENAS),

Jl. PHH. Mustafa No. 23 Bandung, 40124 Indonesia.

Email: waluyo@itenas.ac.id

\section{INTRODUCTION}

High voltage electric generators are essential components of reliable electric power generation system. They must operate continuously and so must be very reliable because a fault in a high voltage generator could compromise the power supply. The continuous operation is critical, so that the on-line diagnosis is the best preventive measure. Furthermore, the faults are largely caused by insulation breakdowns in the stator winding, so that the common method of on-line diagnosis is partial discharge (PD) detection in the stator winding [1].

Generator insulation systems, however perfect their initial state, inevitably degrade in service. Heat, thermal cycling, bar forces, vibration, mechanical shock, shrinkage of support structures, such as wedges and spaces, and the presence of high electric stress, act and interact to impair the integrity of the dielectric systems. At some stages, partial discharges will start and begin to increase, providing an additional erosive aging factor. This usually occurs at abraded outer shielding, in cavities or delaminations, or in the end-turn structure [2].

Partial discharges (PDs) are small electrical sparks resulting from the electrical breakdown that occur when void exist within on the surface or in other highly non-uniform electric field of high voltage insulation of stator windings in generators and motors. These PD pulses can occur because of the manufacturing and installation processes, thermal deterioration, winding contamination or stator bar movement during operation. If the void within an organic solid or liquid, the PD will degrade the organic material and may eventually cause the failure of the electrical insulation. As the insulation degrades, the number and magnitude of the PD pulse will increase. Although the magnitude of the PD pulses cannot be directly related to the remaining life of the winding, the doubling PD pulse magnitudes approximately every 
6 months, rate of PD pulse activity increase rapidly, or the PD levels are highly compared to other similar machines, this is an indicator that visual inspections and/or other testing methods are need to confirm the insulation condition [3],[4].

Partial discharges (PDs) have been recognized as harmful ageing process for electrical insulation at the beginning of the last century when the HV technology was introduced for the generating and transmission of electrical power. Partial discharges are consequence of local electrical stress concentrations in the insulation or on the surface of the insulation. Generally, such discharge appears as pulse having a duration of much less than $1 \mu$ s [5].

Partial discharge comes from different factors, such as thermal, electrical field, environmental ambient and mechanical vibrations. Defects identified by partial discharge measurements are base wedges and bar vibration, slot discharges, broken conductors, contamination of damage of end-winding, discharges between phases as a result of vibration [6].

More than ten years, an extensive research project was undertaken to develop a superior partial discharge test turbine generators. The results were the turbine generator analyzer test, which was designed to be performed by non-specialized generator station staff without a generator outage. The main technical advantage of this test was that false indications of deteriorating insulation were virtually eliminated. The main difficulty in performing an on-line PD test was not in detecting the PD signals, but rather distinguishing the PD from electrical noise. The noise was found to be very erratic overtime, and some time as much as 1000 times higher than generator PD signals. The trend in results from the on-line PD test will give sufficient warning to permit timely modification of generator operation or implementation of relatively inexpensive stator winding maintenance. The on-line PD testing facilitated extending winding life and reduced overall maintenance costs by avoiding in service failures and resulting premature rewinds [7].

The statistical analysis of the data base was the distribution of $\mathrm{Q}_{\mathrm{m}}$ as a function of winding age. The PD results in the data base from machines that were from 1 to more 50 years old showed no consistent trend, which was surprising because one would normally assume that older windings would be more deteriorated and thus have higher PD levels. The inconsistent pattern OPD versus winding age may include the observation that manufacturers of machines have a learning curve to climb as the adopt new design and manufacturing techniques or that utilities are continuously oscillating between proactive and breakdown maintenance strategies, depending on management policies. An analysis of the statistical distribution of PD for several manufacturers was also performed. The cause of the differences between manufacturers was unknown, but it might be due to different manufacturing processes, electric stress design levels and assembly methods [8].

$\mathrm{PD}$ and /or EMI monitoring of hydrogen-cooled generators having tight windings, with or without contamination, does not generally yield additional information on the insulation condition. EMI indications of core-edge and end-winding discharges could not be confirmed by inspection. EMI is effective in identifying problems outside the winding, such as those relating to the iso-phase bus duct components or the exciter. The interpretation of both PD and EMI signatures requires the skill of a trained insulation expert [9].

An effective on-line PD monitoring system must adequately filter and the impact of noise and disturbances in order to provide valid results. The noise and disturbances from the power system and harmonics could influence the quality of PD signals. Absolute humidity should be included in all trend analysis, especially if surface PD monitored for as long as 30 years with the same method of noise and disturbance separation. The on-line partial discharge testing has become a recognized, proven tool to help maintenance engineers identify which stator windings need off line testing, inspection and /or repairs [10].

Matlab Simulink based model has been introduced to generate the pulse and detect it. One sinusoidal ac cycle was taken and divided into 8 segments and the number of pulses appearing for each segments was found by Matlab program. The results for PD pulse count for $5 \mathrm{kV}$ and $10 \mathrm{kV}$. The calibrating circuit was modeled in Matlab Simulink to create desired output PD pulses with required the charge levels as $5 \mathrm{pC}, 10 \mathrm{pC}, 50 \mathrm{pC}, 100 \mathrm{pC}$ and $500 \mathrm{pC}$. The calibrator circuit was connected across the object and output pulses were similar to the calibrating pulses as required. The physical model of calibrator was made and output wave forms were observed on DSO. The output was similar to the simulation results [11].

It has been presented the modern OLPD testing and monitoring technology. It was also explained some partial discharge sensor options, namely high voltage coupling capacitor sensors, high frequency current transformer sensors, Rogowski coil sensors and transient earth voltage sensors. The significant cost and operational benefits could be gained from complete power generation, industrial and petrochemical industry MV networks. The data from continuous CM technology can be used to support CBM schemes and to direct preventive maintenance interventions to repair plat or cables ahead of insulation failure from PD activity [12].

It has been presented some PD detection methods, namely electrical, chemical, acoustic and optical methods of the sensor types. The problems associated with PD for the high voltage equipment and high

Internal On-line Partial Discharge Analysis of 68.75 MVA Generator Stator Winding Insulation (Waluyo) 
voltage power systems have not been ignored and will never be ignored by high voltage system designers and maintenance engineers. PD identification and PD monitoring make economic sense low and many years to come [13].

A positive PD is generated by electrons initiated by collision detachment of negative ions in a high electric field region. Thus, the positive PD generation depends on whether or not negative ions exist around the particle tip. On the other hand, negative PD is generated by an initial electron derived from the field emission from the electrode surface [14]. Partial discharge measurements on operating machines can be influenced by conditions such as humidity, temperature, terminal voltage and load [15].

This research was to analysis and classifies the condition based on the amount of charges per cycle of partial discharge. The partial discharge that monitored was occurred in the 68.75 MVA generator stator winding insulation.

\section{RESEARCH METHOD}

The used measuring method in this research was On-line partial discharge (PD) measurement using resistance temperature detector (RTD) method. This method was to measure the partial discharge that occurred in the generator stator insulation. The illustrated diagram of the measurement is shown in Figure 1 below.

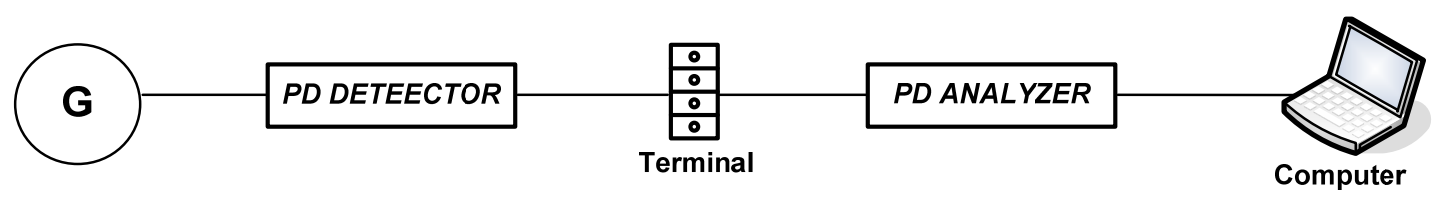

Figure 1. Diagram of partial discharge measurement

The partial discharge measurement used CM $2000^{\mathrm{TM}}$ that connected using a cable from CM2000 ${ }^{\mathrm{TM}}$ to RTD at the generator and ground. The measurement data sampling collection was carried out automatically using a computer and PD monitor software that provided with CM2000.

Diagnosis of partial discharge:

- The measurements were carried out using through the RTD (Resistance Temperature Detector) as a sensor mounted on the generator stator windings.

- The used measuring instrument was Toshiba CM2000 that connects the cable probes from CM2000 to the RTD of generator stator windings.

- The partial discharge magnitudes were measured in millivoltage $(\mathrm{mV})$.

- The data collection was performed automatically using the computer and monitor PD software that available on the CM2000.

\subsection{The terms those need to be considered when testings:}

PD testings should be done in a thermally stable condition.

This meant that the stator winding temperature did not change during testings. Temperature stability was obtained at the of the generator with the same load in a certain time period or until the temperature did not change.

1. PD testings should be done fastly.

If the testings are done fastly, the probability of temperature change will be minimized. The temperature change will influence the comparability and accuracy of testin results. This case will become be important when it is carried out the testings with load variation, such as full load and no load tests after the load is released.

2. The load and the temperature does not change more than a few percent.

When collecting data / partial discharge test, the test should be performed under the same conditions (load and temperature).

3. If the test conditions change, (eg, cooling air humidity), will affect the level of partial discharge and need to be considered in the analysis of partial discharge.

4. When comparing the quantity of partial discharge testing, it is kept in mind the type of used insulation. The different types of insulation are used, it will produce different discharge levels. 
The results of partial discharge testing on generators that are not in synchronous condition with networks, they will be different from the generator in synchronous condition with the network. The partial discharge in generators that are not in synchronous condition with the network will be higher.

The first equipment used in the measurement was RTD PT 100 (resistance temperature detector). RTD or also called as resistance thermometers is a temperature sensor that utilize change of electrical resistance in a certain material to change the temperature. RTD referred to a measure of positive temperature coefficient which means that the resistance will increase with the temperature. PT 100 is a platinum material with condition at $0^{\circ} \mathrm{C}$ temperatures has a resistance of 100 ohms. RTD is used in generators to monitor winding temperature changes due to load current variations. Six pieces of RTD were placed between the topbottom coils so that the change in each coil could be detected.

Figure 2(a) shows the locations of RTD on the generator stator winding. It is indicated in symetrical among them. Figure 2(b) shows the position RTD on the generator stator winding. This figure is the extraction in the sheet of Figure 2(a). The stator winding of phase R (U) was placed and sensed by the RTD probes of B2, C2, B1 and A1. While, the stator winding of phase S (V) was placed and sensed by the RTD probes of C2, A2, C1 and B1. Finally, the stator winding of phase T (W) was placed and sensed by the RTD probes of A2, B2, A1 and C1.

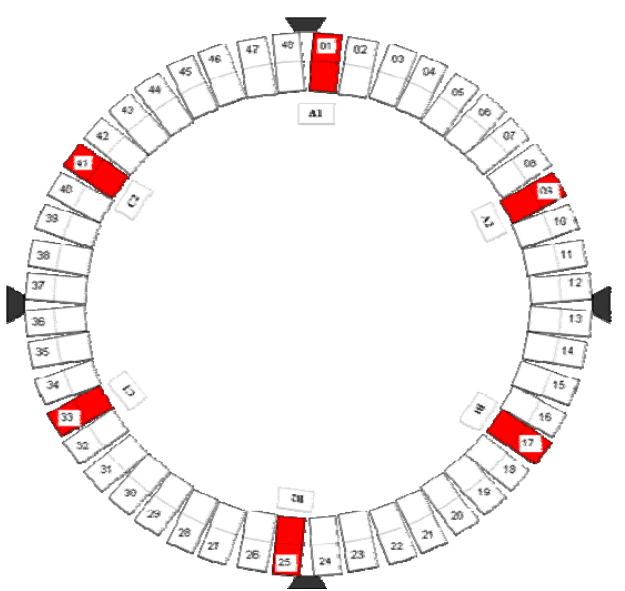

(a) RTD placement

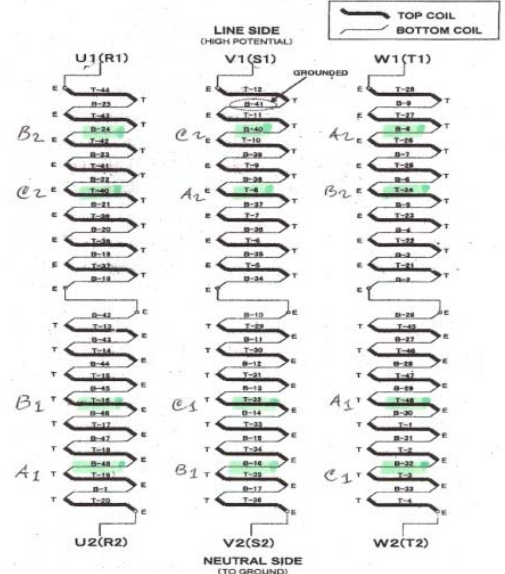

(b) RTD positions

Figure 2. RTD installation and position on the generator stator winding

Table 1 lists the placement of RTD positions. RTD A1 was installed on R and T phases, RTD A2 was installed on $\mathrm{T}$ and S phases and RTD B1 was installed on S and R phases. For same sequence, RTDs of B2, C1 and C2 were installed on R and T phases, $\mathrm{T}$ and $\mathrm{S}$ phases and $\mathrm{S}$ and R phases respectively.

Table 1. Placement of RTDs

\begin{tabular}{ccccc}
\hline \multirow{2}{*}{ RTDs } & \multicolumn{2}{c}{ Placement } & \\
& Position & Slot & Type & Phase \\
\hline A1 & Centre & 1 & Middle & R, T \\
A2 & Exciter & 9 & Long & T, S \\
B1 & Centre & 17 & Middle & S, R \\
B2 & Exciter & 25 & Long & R, T \\
C1 & Centre & 33 & Middle & T, S \\
C2 & Exciter & 41 & Long & S, R \\
\hline
\end{tabular}

Figure 3(a) shows the typical RTD with cable. The equipment was used in the electric generator for partial discharge detections. The second used equipment was CM2000 ${ }^{\mathrm{TM}}$ analyzer of partial discharge measurement system, Figure 3(b) which served to monitor the partial discharge that might occur in the stator generator. Finally, the support tools were BNC coaxial cables including probes with length of 5 meters, as shown in Figure 3(c). 


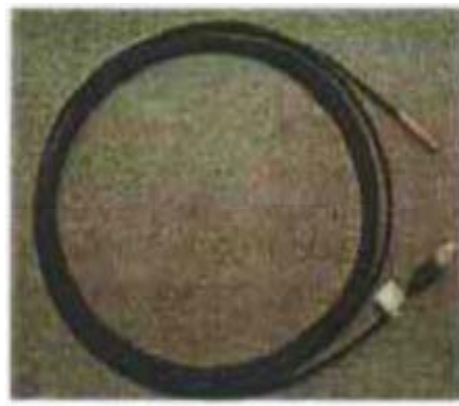

(a) RTD with cable

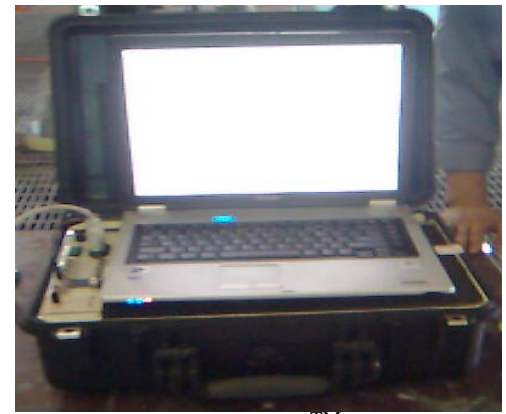

(b) CM2000 ${ }^{\mathrm{TM}}$

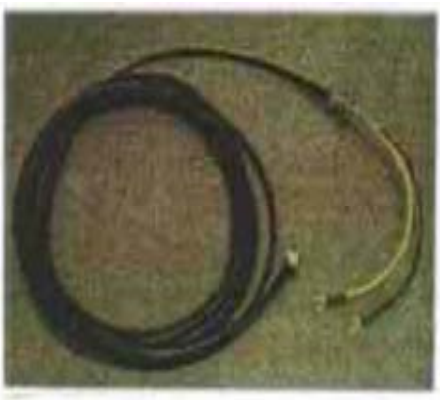

(c) Coaxial cable and BNC probe

Figure 3. CM2000 ${ }^{\mathrm{TM}}$ analyzer of partial discharge measurement system and auxiliary cables

The measurement of partial discharge in high voltage equipment is very important because of the obtained data and their interpretation can be determined a reliability of equipment caused by aging and the risk of failure can be analyzed. The partial discharge test specifications depends on the type of test equipment and insulation materials used in the construction of equipment. The existence of partial discharge in the insulation material can be determined by the method of analysis of the magnitude of the partial discharge. This analysis is one of them can be done by using CM2000 analyzer. It should be noted that this analysis should be careful and always be compared with the data state at an earlier time. The partial discharge data can be good information for the condition of the generator stator winding and thus it can be made of data trends.

Table 2. Interpretation of Partial Discharge [16]

\begin{tabular}{cccc}
\hline No. & PD Measurement results & Interpretation & Remarks \\
\hline 1 & $40 \mathrm{mV}$ & Danger, action required & Action should be taken \\
2 & $30 \mathrm{mV}$ & Detailed analysis to be done & Analysis trend, PD polarity, and \\
3 & $20 \mathrm{mV}$ & PD detected & Monitor time trend \\
4 & $0 \mathrm{mV}$ & No problem found & No action required \\
\hline
\end{tabular}

\section{MEASUREMENT RESULT DATA AND DISCUSSION}

The generator technical data were 3 phase, $50 \mathrm{~Hz}$ frequency, 11,800 Volt, $3000 \mathrm{rpm}$ rotation speed, 68,750 kVA capacity, 0.8 power factor lagging, B insulation class and mica tape with epoxy resin insulating material.

This measurement was performed once a month in a period of 12 months, using six RTD (Resistance Thermal Detector) sensors as the detection tool. The purpose of this measurement to determine the magnitude of the partial discharge that occurs in the generator stator winding insulation. The easurement results are shown in Table 3.

Table 3. The measurement of partial discharge

\begin{tabular}{ccccccc}
\hline \multirow{2}{*}{ Month } & A1 & A2 & B1 & B2 & C1 & C2 \\
\hline 1 & 25.85 & 289.50 & 48.72 & 58.49 & 79.59 & 19.59 \\
2 & 38.82 & 224.18 & 28.28 & 43.72 & 58.54 & 20.32 \\
3 & 29.53 & 394.51 & 10.01 & 59.96 & 58.83 & 20.13 \\
4 & 40.60 & & 29.44 & 0.01 & 50.01 & \\
5 & 45.37 & & & 55.19 & 41.38 & \\
6 & 40.29 & & & 79.56 & & \\
7 & 289.63 & & & 300.13 & & \\
8 & 287.67 & & & 389.99 & & \\
9 & 0.01 & & & 43.84 & & \\
10 & 83.28 & & & 99.39 & & \\
11 & 2.04 & 4.78 & 4.51 & 15.00 & 3.27 & 7.64 \\
12 & 5.40 & 10.07 & 5.98 & 43.30 & 5.96 & 49.80 \\
\hline \multicolumn{7}{c}{} \\
\end{tabular}


The partial discharge voltages those were measured from the RTD sensor represented the conversion of the temperature scale into the amount of voltage. This could be done with the aid of analyzer that could help analyze the partial discharge that occurs in the stator winding voltage generator. The values those occurred during the 12 months fickled.

1. In the first sensor (A1), the maximum voltage of partial discharge was occurred in the seventh month $(289.63 \mathrm{mV})$ and the minimum voltage of partial discharge was occurred at month of nine $(0.01 \mathrm{mV})$.

2. In the second sensor (A2), the maximum voltage of partial discharge was occurred in third month (394.51 $\mathrm{mV})$ and the minimum voltage of partial discharge was occurred in the eleventh month $(4.78 \mathrm{mV})$.

3. In the third sensor (B1), the maximum voltage of partial discharge was occurred in the first month (48.72 $\mathrm{mV}$ ) and the minimum voltage of partial discharge was occurred in the elevent month (4.51 $\mathrm{mV})$.

4. In the fourth sensor (B2), the maximum voltage of partial discharge was occurred in the eighth month $(389.99 \mathrm{mV})$ and the minimum voltage of partial discharge was occurred in the fourth months $(0.01 \mathrm{mV})$.

5. In the fifth sensor (C1), the maximum voltage of partial discharge was occurred in the first month (79.59 $\mathrm{mV}$ ) and the minimum voltage of partial discharge was occurred in the eleventh month $(3.27 \mathrm{mV})$.

6. In the sixth sensor (C2), the maximum voltage of partial discharge was occurred at twelfth month (49.80 $\mathrm{mV}$ ) and the minimum voltage of partial discharge was occurred in the eleventh month $(7.64 \mathrm{mV})$.

The trend data of partial discharge measurement results in the generator stator winding appears that most of the partial discharge activity tent to increase, especially in the month of seventh and eighth.

Based on the direct measurements, it was classified into three conditions based on the amount of charges per cycle. Figure 13 shows the partial discharge occurs those caused by internal void in the generator stator insulation. These cases were indicated by the amount of charge occupied on the positive parts of cycles those have almost same amount of those on the negative ones.
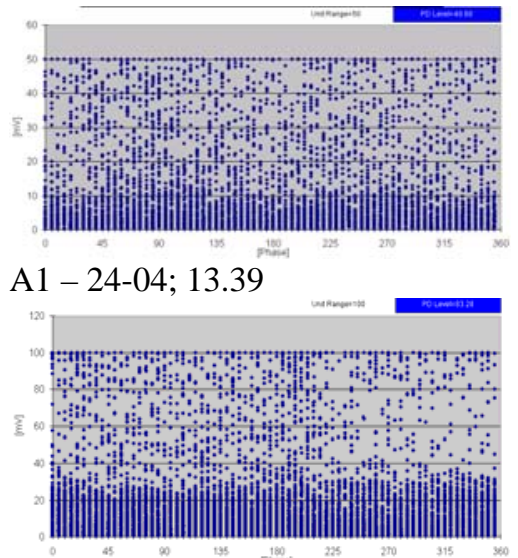

A1 - 09-10; 13.15

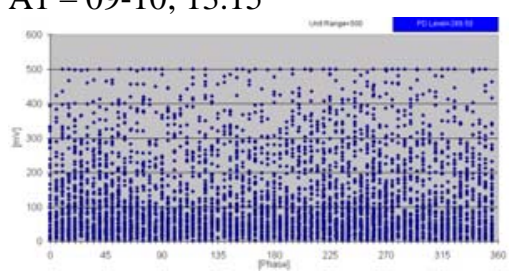

A2 - 29-01; 10.40

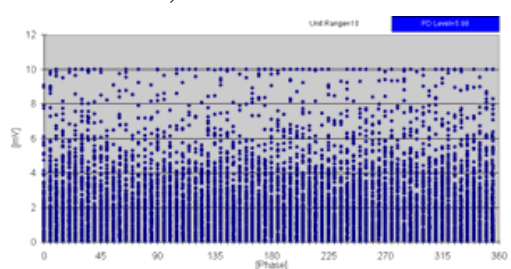

B1 - 30-12; 14.05
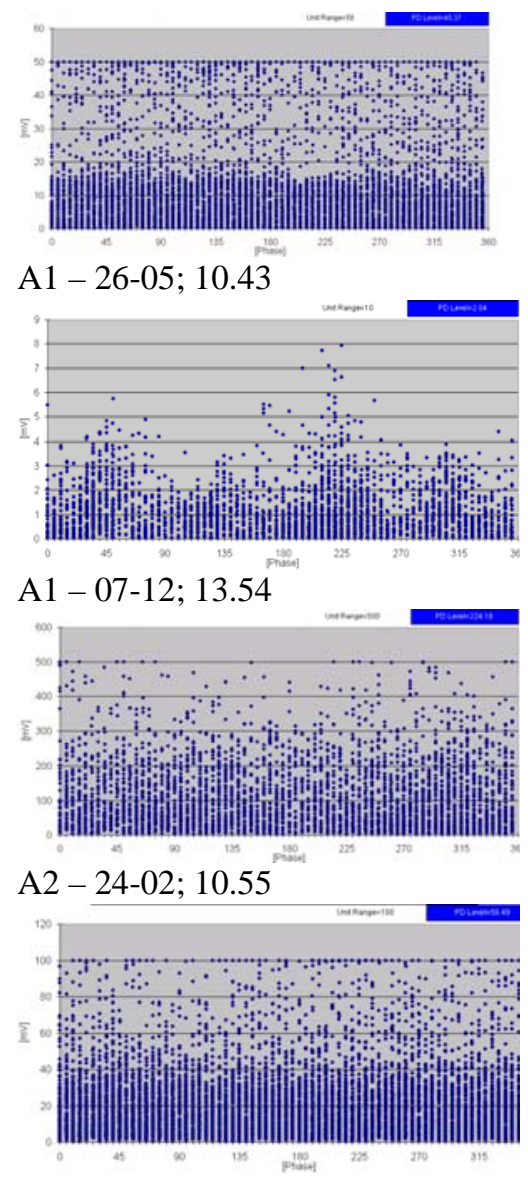

B2 - 29-01; 10.56
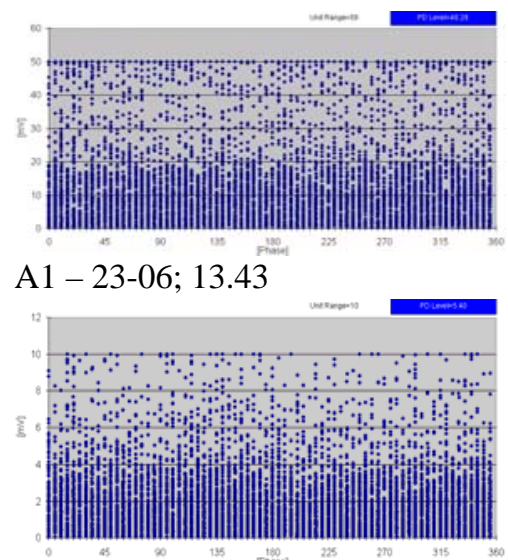

A1 - 30-12; 13.33

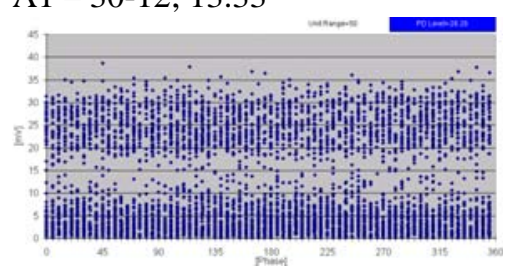

B1 - 24-02; 11.03

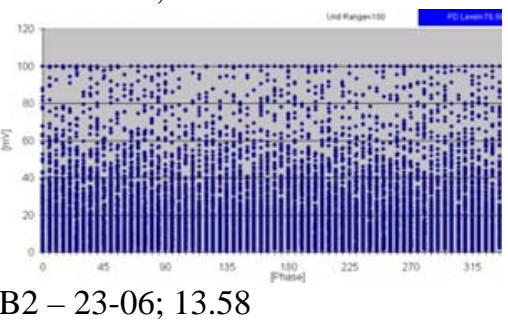



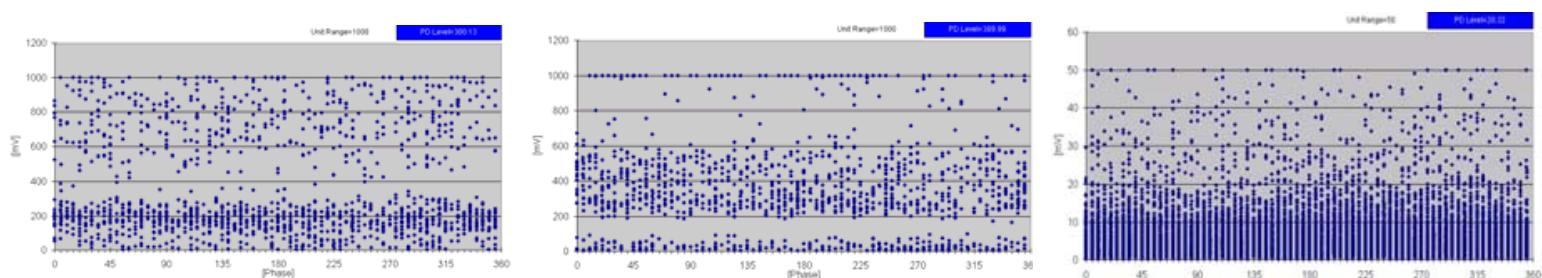

B2 - 06-08; 11.37

B2 - 28-08; 14.05

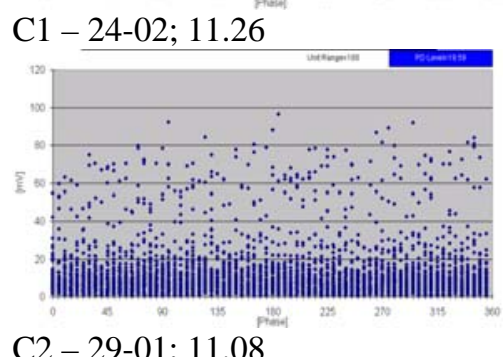

C1 - 24-04; 14.45

C1 - 26- $05 ; 22.52$

C2 - 29-01; 11.08

Figure 13. The measurement results those the positive and negative cycles have almost same charges

The second condition, as shown in Figure 14, indicated the internal delamination. In the internal delamination, the insulation would be separated from the copper conductor; therefore it would be weakly bonded, overheating, and so forth. This case could be seen from the most charge was on the negative cycles was more dominant than on the negative cycle ones.

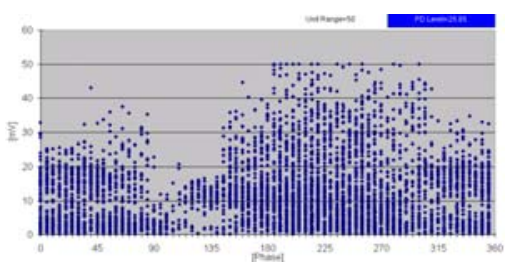

A1 - 29-01; 10.31

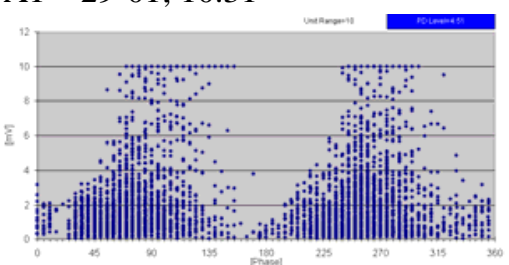

B1 - 07-12; 14.27

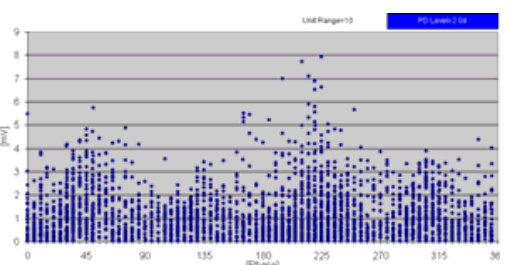

A1 - 07-12; 13.54

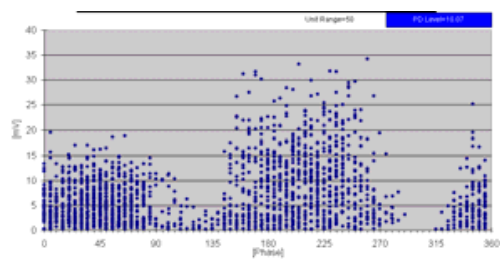

A2 - 30-12; 13.59

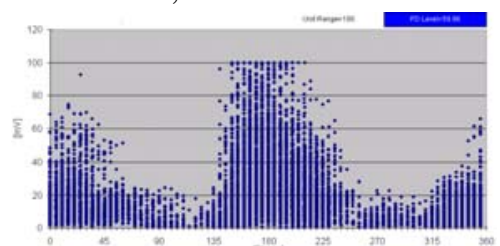

B2 - 25-03; 11.14

Figure 14. The measurement results those the charge on the negative cycles were more dominant than those on the negative ones

The third condition of measurement indicated the surface discharges. This phenomenon was caused by semi conductive a material (paint) was damage and loose its capability, as shown Figure 15.

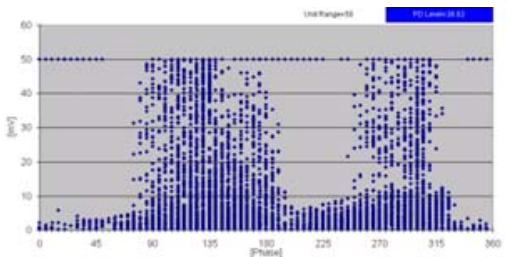

A1 - 24-02; 09.42

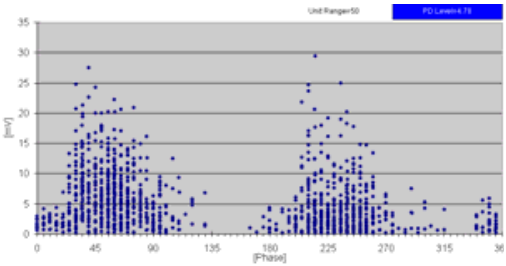

A2 - 07-12; 14.01

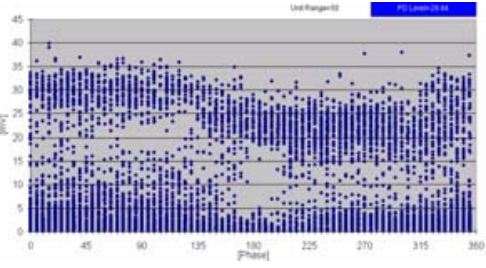

B1 - 24-04; 14.31 


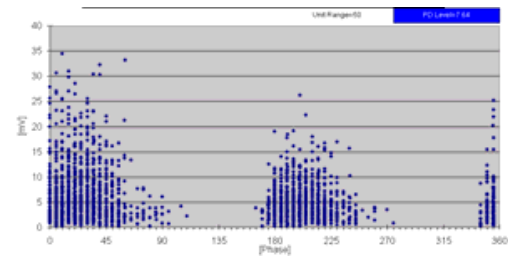

C2 - 07-12; 14.56

Figure 15. This phenomenon was caused by semi conductive a material (paint)

\section{CONCLUSION}

Based on the measurement for 12 months, the partial discharge occurs in the generator unit 2 was almost caused by the internal void in the generator insulation. This case was indicated by the charge on the positive cycles almost same with on the negative once. The greatest energy of partial discharge was occurred in third month, and followed by one in eighth months. These cases indicated the discharge occurs, therefore the condition of the stator winding insulation has changed from the normal condition.

\section{ACKNOWLEDGEMENTS}

We would like to express the deepest appreciation to Indonesia Power, The Geothermal Power Plant Unit of Kamojang, which has supported to provide the data.

\section{REFERENCES}

[1] H. Shin, et al., "Denoising of On-line Partial Discharge Signal from High-Voltage Rotating Machines using Standard Deviation Threshold," International Journal of Innovatives Computing, Information and Control, vol/issue:7(A), pp. 3761-3769, 2011. ISSN 1349-4198.

[2] M. Kurtz and G. C. Stone, "In-Service Partial Discharge Testing of Generator Insulation,” IEEE Transaction on Electrical Insulation, vol/issue: EI-14(2), 1979.

[3] G. C. Stone, "Partial Discharge Diagnosis and Electrical Equipment Insulation Condition Assessment," IEEE Transaction on Dielectrics and Electrical Insulation, vol/issue: 12(5), pp. 891-904, 2005.

[4] V. Warren, "Partial Discharge Testing: A Progress Report," Statistical Evaluation of PD Data, Irish Rotating Machine Conference, San Antonio, Tx., USA, June, 2007.

[5] E. Lemke, et al., "Guide for Electrical Partial Discharge Measurements in Compliance to IEC 60270,” Electro, vol. 241, Technical Brochure 366, WG D1.33, pp. 61-67, 2008.

[6] PD Tech Power Engineering AG, "Partial Discharge Basics of Monitoring," Micamaxx ${ }^{\mathrm{TM}}$ Plus-Partial Discharge Basics, pp. 1-18.

[7] H. G. Sedding, et al., “A New On-Line Partial Discharge Test for Turbine Generators,” Cigre, 1992 Session, \#0 August - 5 September, pp. 1-7, 1992.

[8] G. C. Stone and V. Warren, "Effect of Manufacturer Winding Age and Insulation Type on Stator Winding Partial Discharge Levels,” From DEIS, Sept-Oct 2004, vol/issue: 20(5), pp. 13-17, 2004.

[9] J. K. Nelson and J. Stein, “A Field Assessment of PD and EMI Methodology Applied to Large Utility Generators," IEEE Transactions on Dielectrics and Electrical Insulation, vol/issue: 17(5), pp. 1411-1427, 2010. ISSN: 1070 9878.

[10] V. Warren, “Stator Winding Partial Discharge Activity for Marine Air-Cooled Generators,” FMMS 2013 of ASNE Conference, August, 2013.

[11] A. K. Gupta, et al., "Modeling of Calibration Circuit for Partial Discharge Measurement," Thesis, Department of Electrical Engineering, National Institute of Technology, Rourkela, Odisha, pp. 13-42, 2013.

[12] L. Renforth, et al., "Continuous, Remote On-line Partial Discharge (OLPD) Monitoring of Complete Medium Voltage (MV) Network,” pp. 1-11.

[13] M. M. Yaacob, et al., "Review on Partial Discharge Detection Techniques Related to High Voltage Power Equipment using Different Sensors,” Photonic Sensors, vol/issue: 4(4), pp. 325-337, 2014.

[14] U. Khayam, et al., "Partial Discharge and Cross Interference Phenomena i a Three-Phase Construction," International Journal on Electrical Engineering and Informatics, vol/issue: 1(1), pp. 85, 2009.

[15] B. A. Lloyd, et al., "Continuous On-line Partial Discharge Monitoring of Generator Stator Windings," IEEE Transaction on Energy Conversion, vol/issue: 14(4), pp. 1131-1138. ISSN: 0885-8969.

[16] Toshiba, "Instruction Manual; CM2000 Specifications,” Toshiba International Corporations, Pty., Ltd. 